\title{
Estudo etnobotânico das árvores medicinais do Parque Ecológico Municipal José Milanese, Criciúma, Santa Catarina, Brasil
}

TOMAZI, L.B. ; AGUIAR, P.A. ${ }^{2,3}$; CITADINI-ZANETTE, V. ${ }^{2,3}$; ROSSATO, A.E. ${ }^{2 *}$

${ }^{1}$ Curso de Farmácia - UNESC (Egressa). ${ }^{2}$ Grupo de Extensão e Pesquisa em Plantas Medicinais (GEPPLAM/ UNESC). ${ }^{3}$ Programa de Pós-Graduação em Ciências Ambientais (PPGCA) da Universidade do Extremo Sul Catarinense - UNESC, Av. Universitária, 1105, CEP 88806-000, Criciúma, Santa Catarina. *aerossato@ gmail.com

RESUMO: O presente estudo foi realizado no Parque Ecológico Municipal José Milanese (PEMJM), localizado no Bairro Mina União, no Município de Criciúma, Santa Catarina - Brasil, tendo como objetivo realizar levantamento etnobotânico no PEMJM sobre as 31 árvores medicinais descritas por Figueiró-Leandro \& Citadini-Zanette (2008), junto aos moradores do entorno do referido parque, detentores do conhecimento com plantas medicinais. Os dados foram coletados no período de fevereiro a abril de 2008 por meio de entrevistas semiestruturadas realizadas nas residências dos informantes. Das 31 árvores medicinais presentes no PEMJM, 14 foram citadas pelos entrevistados, atribuindo a elas, 42 indicações terapêuticas. Os farmacógenos mais utilizados foram: folhas $(76,25 \%)$ e cascas $(12,5 \%)$. As formas mais expressivas de preparo foram: o decocto $(36,25 \%)$, e o infuso $(28,75 \%)$. Em relação às indicações terapêuticas destacaram-se três espécies: Casearia sylvestris Sw. (guaçatonga) e Jacaranda puberula Cham. (carobinha), com nove indicações cada uma, e Zollernia ilicifolia (Brongn.) Vogel (carapicica-de-folha-lisa), com oito indicações. Muitas das indicações terapêuticas relatadas neste estudo não constam na literatura consultada por Figueiró-Leandro \& Citadini-Zanette (2008) evidenciando a necessidade de mais pesquisas sobre essas plantas e a importância do registro das informações populares.

Palavras-chave: saber popular, plantas medicinais, Floresta Atlântica, Sul de Santa Catarina

ABSTRACT: Ethnobotany survey of medicinal trees of the José Milanese Municipal Ecological Park, city of Criciúma, state of Santa Catarina - Brazil. This study was carried out at the José Milanese Municipal Ecological Park (PEMJM), located in Mina União, municipality of Criciúma, state of Santa Catarina - Brazil, aiming to do an ethnobotanical survey of the 31 medicinal trees described by Figueiró-Leandro \& Citadini-Zanette (2008) in the PEMJM together with the surrounding residents of that park, who possess knowledge of medicinal plants. The data were collected from February to April 2008 through semi-structured interviews, which were held in the houses of the respondents. From 31 medicinal trees present in the Park, 14 were mentioned by the respondents, giving to such trees 42 therapeutic indications. The most used pharmacogens were the leaves $(76.25 \%$ ) and barks (12.5\%), and among the ways of preparation the most revealing ones were in the form of decoction (36.25\%) and infusion $(28.75 \%)$. In relation to therapeutic indications, three tree species were mentioned: Casearia sylvestris Sw. and Jacaranda puberula Cham. with nine indications, and Zollernia ilicifolia (Brongn.) Vogel with eight indications. Many of the therapeutic indications reported in this study are not in the literature verified by Figueiró-Leandro \& Citadini-Zanette (2008), which shows the necessity of carrying out more research studies on such plants and the importance of registering popular information.

Keywords: folk knowledge, medicinal plants, Atlantic Forest, South of the state of Santa Catarina

\section{INTRODUÇÃO}

A utilização das plantas para cura é uma forma de tratamento muito antiga, relacionada aos primórdios da medicina e fundamentada no acúmulo de informações obtidas de sucessivas gerações. Ao longo dos séculos, produtos de origem vegetal constituíram as bases para tratamento de diferentes 
doenças (Corrêa et al., 2002). Hoje, o seu uso não se restringe às zonas rurais (Marodin \& Baptista, 2001) ou a regiões desprovidas de assistência médica e farmacêutica (Alonso, 2008). Tudo indica que elas são utilizadas intensamente no meio urbano, como forma alternativa ou complementar aos medicamentos da medicina oficial (Simões et al., 1998).

Dados da Organização Mundial de Saúde (OMS) mostram que cerca de $80 \%$ da população mundial fazem uso de algum tipo de erva, buscando alívio para sintomas dolorosos ou desagradáveis (OMS, 2000) e a OMS tem encorajado o estudo de plantas tradicionais, com a esperança de validá-las e evitar sua utilização irracional (WHO, 2003).

No Brasil, no ano de 2009, o Programa Nacional de Plantas Medicinais e Fitoterápicos do Ministério da Saúde elaborou e divulgou a Relação de Plantas Medicinais de Interesse para o Sistema Único de Saúde (RENISUS). Esta relação apresenta 71 plantas medicinais que apresentam potencial para gerar produtos de interesse ao Sistema Único de Saúde (SUS). A finalidade da RENISUS é subsidiar o desenvolvimento de toda cadeia produtiva, inclusive nas ações que serão desenvolvidas também pelos outros ministérios participantes do Programa Nacional de Plantas Medicinais e Fitoterápicos, relacionadas à regulamentação, cultivo/manejo, produção, comercialização e dispensação de plantas medicinais e fitoterápicos. Terá também a função de orientar estudos e pesquisas que possam subsidiar a elaboração da RENAFITO (Relação Nacional de Plantas Medicinais e Fitoterápicos), o desenvolvimento e a inovação na área de plantas medicinOs estudos com plantas medicinais têm sido responsáveis por inúmeras e importantes descobertas. O desenvolvimento desta área de pesquisa deve-se a vários fatores, dos quais, se destaca a participação numérica cada vez maior de profissionais. No entanto, resultados promissores dependem de maior inter-relação entre conhecimento popular, profissionais de diversas áreas, e disciplinas integradas que compõem o estudo das plantas medicinais, pois a continuidade de tais estudos de forma isolada poderá acarretar na falta de resultados, impedindo consequentemente o desenvolvimento de novos medicamentos e o uso racional de fitoterápicos (Di Stasi, 1996).

No entanto, os conhecimentos tradicionais, se enriquecidos pelo conhecimento científico ocidental, podem ser desenvolvidos tanto em nível local das comunidades estudadas, como em níveis mais amplos, dentro de programas regionais de desenvolvimento, como parte de estratégia política para o intercâmbio social (Caballero, 1983).

Neste contexto, o objetivo deste trabalho foi realizar, junto à comunidade do Bairro Mina
União, Município de Criciúma, Santa Catarina, o levantamento etnobotânico das 31 árvores medicinais descritas por Figueiró-Leandro \& Citadini-Zanette (2008) presentes no PEMJM, a fim de registrar o conhecimento popular e, quiçá, fornecer dados para futuras pesquisas que visem a comprovar a eficácia e a segurança destas plantas medicinais.

\section{MATERIAL E MÉTODO}

\section{Área de estudo}

O Município de Criciúma, localizado no Sul de Santa Catarina, possui 187.018 habitantes e extensão territorial de $236 \mathrm{~km}^{2}$ (IBGE, 2008), com altitude de $46 \mathrm{~m}$. Neste município, no Bairro Mina União, está localizado o Parque Ecológico Municipal José Milanese (PEMJM). O Parque situa-se entre as coordenadas $28^{\circ} 48^{\prime} \mathrm{S}$ e $49^{\circ} 25^{\prime} \mathrm{W}$, altitude média de $34 \mathrm{~m}, \operatorname{com} 7,7$ ha de área, sendo 5,2 ha cobertos pela Floresta Ombrófila Densa Submontana, pertencente ao bioma Mata Atlântica. Esta Floresta passou por corte seletivo nos anos 80 , porém ainda conserva características de floresta primária (Figueiró-Leandro \& Citadini-Zanette, 2008).

A região estudada, segundo a Classificação de Köppen, pertence ao grupo climático Cfa, ou seja, mesotérmico úmido, sem estação seca definida e com verão quente (Ometto, 1981). A umidade relativa anual está entre 80 e $85 \%$ e a precipitação média de 1.400 a $1.600 \mathrm{~mm}^{\text {ano-1 }}{ }^{-1}$, não havendo índices pluviométricos mensais inferiores a 60 $\mathrm{mm}$ (EPAGRI, 2001). O solo é caracterizado como Podzólico Vermelho-Amarelo Latossólico Álico e Podzólico Vermelho-Amarelo Álico (Santa Catarina, 1986).

\section{Metodologia}

O levantamento etnobotânico foi realizado com os moradores da comunidade do Bairro Mina União, que detinham amplo conhecimento sobre o uso medicinal das 31 árvores descritas por Figueiró-Leandro \& Citadini-Zanette (2008) com potencialidades medicinais encontradas no PEMJM.

Para compor a amostra, foram selecionados para a entrevista agentes da Pastoral da Saúde do Bairro Mina União e indivíduos da comunidade local que detinham amplo conhecimento sobre o uso medicinal das árvores presentes no Parque Ecológico Municipal José Milanese. A escolha dos informantes foi feita por indicação resultante de conversas informais com moradores da comunidade (Albuquerque et al., 2010), resultando em cinco informantes identificados e indicados pela comunidade como detentores do conhecimento sobre plantas medicinais.

Rev. Bras. PI. Med., Campinas, v.16, n.2, supl. I, p.450-461, 2014. 
Para a coleta dos dados foi elaborado um questionário (Anexo 1), tendo como referência a literatura pertinente ao estudo etnobotânico, mediante Declaração de Consentimento Informado, em forma de entrevista semiestruturada no período de fevereiro a abril de 2008 na residência dos entrevistados. O estudo foi aprovado pelo Comitê de Ética em Pesquisa em Humanos da Universidade do Extremo Sul Catarinense, UNESC (Parecer $n^{\circ}$ 340/2006).

Com base nas espécies arbóreas selecionadas por Figueiró-Leandro \& CitadiniZanette (2008), foi confeccionada uma pastaarquivo das 31 árvores medicinais, onde constavam imagens da árvore adulta e detalhe de um ramo florífero e/ou vegetativo, informações sobre suas características botânicas, juntamente com um exemplar herborizado (duplicata de exsicata), proveniente do acervo do Herbário Pe. Dr. Raulino Reitz (CRI), da UNESC. Estas imagens e as plantas desidratadas foram apresentadas aos entrevistados visando o reconhecimento das espécies e a coleta das informações.

As entrevistas foram registradas em gravador de audio, sendo posteriormente transcritas e depositadas em local seguro para averiguação da veracidade das informações, se solicitadas.

Os dados, organizados no formato de texto e tabelas, foram analisados e comentados com base nas informações obtidas e na bibliografia pertinente. Nas tabelas, a terminologia utilizada para os usos e nomes populares das plantas, corresponde aos mencionados pelos entrevistados.

\section{RESULTADO E DISCUSSÃO}

A faixa etária dos cinco entrevistados esteve na faixa de 50 a 89 anos, sendo quatro pertencentes ao sexo feminino, todos casados e nascidos no perímetro rural. Relataram que cultivam as árvores medicinais em casa, e quando não as possuem, encontram-nas facilmente em matas fechadas e terrenos abandonados, próximos às suas residências. Um dos entrevistados relatou que, quando utiliza seca, as obtém em farmácias.

Das 31 árvores registradas como medicinais por Figueiró-Leandro \& Citadini-Zanette (2008), 14 delas $(45,16 \%)$ são utilizadas e conhecidas dos entrevistados, sendo Casearia sylvestris (guaçatonga) e Zollernia ilicifolia (carapicica-defolha-lisa) citadas quatro vezes. Jacaranda puberula (carobinha) e Ocotea odorifera (canela-sassafrás) foram citadas três vezes.

As outras árvores, Psidium cattleianum (araçá) e Trema micrantha (grandiúva) foram mencionadas duas vezes, enquanto Allophylus edulis (vacum, chal-chal), Cabralea canjerana (canjerana), Cecropia glaziovii (embaúba), Cedrela fissilis (cedro), Euterpe edulis (palmiteiro), Magnolia ovata (baguaçu), Ocotea indecora (canela) e Zanthoxylum rhoifolium (mamica-de-cadela) foram citadas apenas uma vez.

As árvores com propriedades medicinais mencionadas pertencem a 12 famílias, $54,54 \%$ das registradas por Figueiró-Leandro \& Citadini-Zanette (2008). Lauraceae e Meliaceae apresentaram duas espécies e as demais apenas uma (Tabela 1).

Para as 14 árvores medicinais citadas e utilizadas pelos entrevistados, 42 indicações terapêuticas foram mencionadas durante as entrevistas. As indicações mais citadas foram para o tratamento do reumatismo e do colesterol com seis citações cada e para o tratamento da diabetes e circulação, ambas citadas três vezes.

O farmacógeno mais utilizado foram as folhas $(76,25 \%)$, seguido da casca $(12,5 \%)$, raiz $(7,5 \%)$, flores $(2,5 \%)$ e "coração" (broto apical da inflorescência) com 1,25\%.

É importante observar que diferentes partes da mesma planta são utilizadas de várias maneiras para a mesma afecção ou para afecções distintas. De acordo com os entrevistados, por exemplo, o infuso das flores de Ocotea odorifera (canelasassafrás) serve para tratar reumatismo, ou, a tintura da casca, para tratar doença-da-gota (Tabela 1).

Entre as formas de preparo foram citadas: decocto $(36,25 \%)$, infuso $(28,75 \%)$, tintura pela técnica da maceração $(17,5 \%)$, decocto para lavagem externa $(11,25 \%)$, e xarope $(6,25 \%)$. Entre os solventes utilizados, predominou a utilização da água $(76,5 \%)$ em relação aos outros solventes. Álcool cereal + água obteve percentual de 16,04\%, seguido de açúcar mascavo + água (3,7\%), laranja inteira + açúcar mascavo + água + cachaça $(2,46 \%)$ e vinagre $(1,3 \%)$, conforme mostrado na Tabela 1.

Dentre as árvores com mais indicações terapêuticas, destacaram-se: Casearia sylvestris (guaçatonga) e Jacaranda puberula (carobinha) com nove indicações cada uma; e Zollernia ilicifolia (carapicica-de-folha-lisa) com oito indicações, sendo estas as árvores mais utilizadas e citadas pelos informantes.

Sobre Casearia sylvestris, foram obtidos os seguintes relatos:

Relato 1: "[...] tem que ter cuidado porque tem que ser feito só na parte da manhã, põe só uma folhinha, e usado por quinze dias, depois pára, dá um intervalo, porque destrói a flora intestinal, dá diarréia mesmo [...] e emagrece; é muito diurética, tem que ter muito cuidado [...] porque se a pessoa urina bastante [...] perde o que? perde cálcio, magnésio [...] daí vai dar dor nas pernas, vai dá câimbra."

Relato 2: "[...] eu uso também pra xarope

Rev. Bras. PI. Med., Campinas, v.16, n.2, supl. I, p.450-461, 2014. 
TABELA 1. Espécies arbóreas encontradas no PEMJM, utilizadas e conhecidas como medicinais pelos entrevistados, suas respectivas famílias, nomes científicos e populares, indicações terapêuticas, partes utilizadas, formas de uso e solventes utilizados. Os numerais de 1 a 5 correspondem à codificação dada aos informantes.

\begin{tabular}{|c|c|c|c|c|c|}
\hline \multirow{2}{*}{$\begin{array}{l}\text { Família } \\
\text { Nome científico }\end{array}$} & \multicolumn{5}{|c|}{ Informações advindas dos entrevistados } \\
\hline & Nome popular & Indicação terapêutica & $\begin{array}{c}\text { Parte } \\
\text { utilizada }\end{array}$ & $\begin{array}{c}\text { Forma de } \\
\text { Uso }\end{array}$ & $\begin{array}{l}\text { Solvente } \\
\text { utilizado }\end{array}$ \\
\hline \multirow{2}{*}{$\begin{array}{l}\text { Arecaceae } \\
\text { Euterpe edulis Mart. }\end{array}$} & \multirow{2}{*}{$\begin{array}{l}\text { Palmiteiro } \\
\text { (1) }\end{array}$} & Reumatismo, doença-da-gota & Raiz fresca & Tintura & $\begin{array}{c}\text { Álcool cereal e } \\
\text { água }\end{array}$ \\
\hline & & Chia, colesterol & Raiz fresca & Decocto & Água \\
\hline \multirow{3}{*}{$\begin{array}{l}\text { Bignoniaceae } \\
\text { Jacaranda puberula } \\
\text { Cham. }\end{array}$} & \multirow{3}{*}{$\begin{array}{l}\text { Carobinha } \\
(1,2,5)\end{array}$} & $\begin{array}{c}\text { Alergias }(1,2,5) \text {, frieira (1), } \\
\text { inflamação }(2) \text {, doenças-de-pele (2), } \\
\text { sarna }(5), \text { cobreiro (5) }\end{array}$ & Folhas & $\begin{array}{l}\text { Lavagem } \\
\text { externa }\end{array}$ & Água \\
\hline & & Tosse (1), bronquite alérgica (1) & Folhas & Xarope & $\begin{array}{c}\text { Água + açúcar } \\
\text { mascavo + } \\
\text { laranja inteira + } \\
\text { cachaça } \\
\end{array}$ \\
\hline & & Intoxicação do veneno de roça (1) & Folhas & Infuso & Água \\
\hline $\begin{array}{l}\text { Cannabaceae } \\
\text { Trema micrantha } \\
\text { (L.) Blume }\end{array}$ & $\begin{array}{c}\text { Grandiúva } \\
(1,2)\end{array}$ & $\begin{array}{c}\text { Dor na coluna (1), bico de papagaio } \\
\text { (1), reumatismo (1), fortalecer o } \\
\text { aleitamento (2) }\end{array}$ & Folhas & Infuso & Água \\
\hline $\begin{array}{l}\text { Fabaceae } \\
\text { Zollernia ilicifolia } \\
\text { (Brongn.) Vogel }\end{array}$ & $\begin{array}{l}\text { Carapicica-de- } \\
\text { folha-lisa } \\
(1,2,3,4)\end{array}$ & $\begin{array}{l}\text { Dor nas costas (1), úlceras }(1,3,4) \text {, } \\
\text { dor de barriga (1), artrite (1), calmante } \\
\text { (1), tumor de esôfago (1), estômago } \\
(3,4) \text {, congestão (2) }\end{array}$ & Folhas & Decocto & Água \\
\hline $\begin{array}{l}\text { Lauraceae } \\
\text { Ocotea indecora } \\
\text { (Schott) Mez. }\end{array}$ & $\begin{array}{c}\text { Canela } \\
\text { (2) }\end{array}$ & Dor no estômago, resfriado, gripe & Folhas & Decocto & Água \\
\hline \multirow{6}{*}{$\begin{array}{l}\text { Lauraceae } \\
\text { Ocotea odorifera } \\
\text { (Vell.) Rohwer }\end{array}$} & \multirow{6}{*}{$\begin{array}{l}\text { Canela } \\
(1,2,3)\end{array}$} & \multirow{3}{*}{ Reumatismo $(1,3)$} & Casca & Tintura (1) & $\begin{array}{c}\text { Álcool cereal e } \\
\text { água }\end{array}$ \\
\hline & & & Casca & $\begin{array}{l}\text { Decocto } \\
\text { (3) }\end{array}$ & Água \\
\hline & & & Flores & Infuso (3) & Água \\
\hline & & Doença da gota (1) & Casca & Tintura & $\begin{array}{c}\text { Álcool cereal e } \\
\text { água }\end{array}$ \\
\hline & & Artrose (3) & Flores & Infuso & Água \\
\hline & & Tosse (2) & Folhas & Infuso & Água \\
\hline $\begin{array}{l}\text { Meliaceae } \\
\text { Cabralea canjerana } \\
\text { (Vell.) Mart. }\end{array}$ & $\begin{array}{l}\text { Canjerana } \\
\text { (1) }\end{array}$ & Adstringente, diabetes & Folhas & Infuso & Água \\
\hline $\begin{array}{l}\text { Meliaceae } \\
\text { Cedrela fissilis Vell. }\end{array}$ & $\begin{array}{c}\text { Cedro } \\
(1)\end{array}$ & $\begin{array}{l}\text { Reumatismo, circulação, depurativo } \\
\text { do sangue }\end{array}$ & Folhas & Infuso & Água \\
\hline $\begin{array}{l}\text { Magnoliaceae } \\
\text { Magnolia ovata }\end{array}$ & Baguaçu & Cirrose hepática, reumatismo & Folhas & Tintura & $\begin{array}{l}\text { Álcool cereal e } \\
\text { água }\end{array}$ \\
\hline (A.St.-Hil.) Spreng. & & Infecção no útero & Folhas & Decocto & Água \\
\hline $\begin{array}{l}\text { Myrtaceae } \\
\text { Psidium cattleianum } \\
\text { Sabine }\end{array}$ & $\begin{array}{l}\text { Araçá } \\
(1,2)\end{array}$ & Diarréia, dor de barriga $(1,2)$ & Folhas & Decocto & Água \\
\hline
\end{tabular}


TABELA 1. Espécies arbóreas encontradas no PEMJM, utilizadas e conhecidas como medicinais pelos entrevistados, suas respectivas famílias, nomes científicos e populares, indicações terapêuticas, partes utilizadas, formas de uso e solventes utilizados. Os numerais de 1 a 5 correspondem à codificação dada aos informantes.

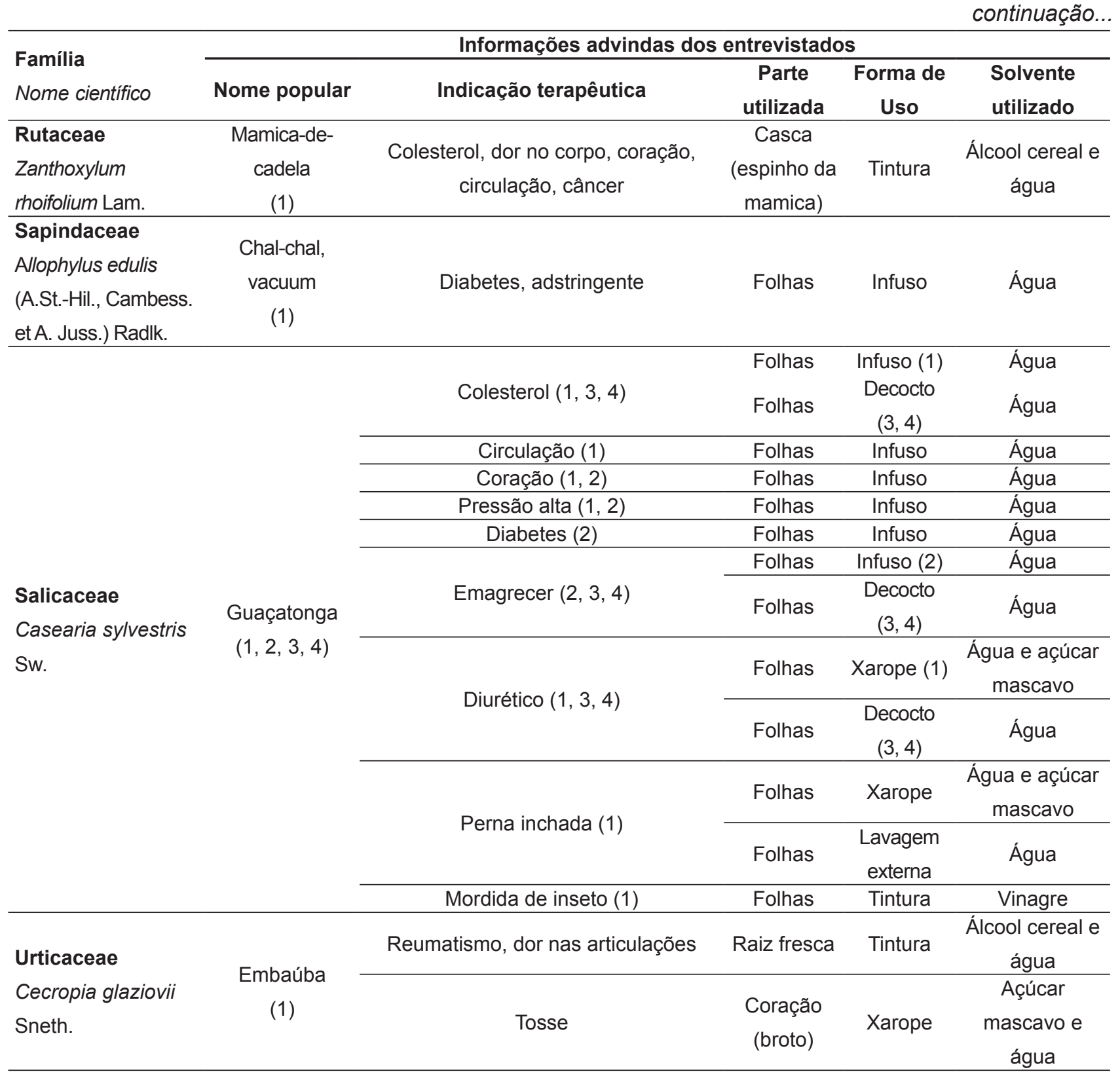

porque as pessoas pedem pra fazer porque elas não urinam e tem as pernas inchadas [...] então ai eu faço só com ela, pego várias folhas, no mínimo 10 a 12 folhas, ai eu boto dentro do açúcar mascavo, derreto as folhas e vai queimando, quando eu vejo que tá queimadinho, aí eu jogo 1 litro de água dentro e peço pra ir tomando durante o dia [...] é uma dose única."

Relato 3: "[...] a guaçatonga é ótima, qué vê pra mordida de inseto, deixa de molho no vinagre, só a folha e o vinagre, deixar ela curtir, qualquer mordida de inseto, passa e é pra já."

Os dois primeiros relatos evidenciam a necessidade de ingerir a guaçatonga com muito cuidado, por ser esta planta bastante diurética. Segundo Guyton \& Hall (1997), diurético é a substância que aumenta a taxa do débito do volume urinário, como o nome sugere, fazendo com que haja consequentemente aumento da excreção urinária dos solutos, especialmente sódio e cloreto. O uso indiscriminado de $C$. sylvestris em pacientes prédisponíveis à gota pode agravar a doença, já que a perda excessiva de água favorece a precipitação de cristais de acido úrico. Este fato evidencia a importância da utilização segura e racional das 
plantas medicinais, mesmo por que estas não estão isentas de efeitos colaterais, contraindicações, interações medicamentosas e toxicidade (VeigaJunior et al., 2005).

Já no terceiro relato, o entrevistado destaca a importância da $C$. sylvestris naquela região e a satisfação em utilizá-la. A ação para a picada de insetos é também citada por Körbes (1995), Franco (2001) e Franco \& Fontana (2001).

Relatos interessantes também foram citados pelos entrevistados, sobre Jacaranda puberula, para uso externo em feridas, alergias, dentre outras: "[...] é feito o chá (das folhas) e lavado externamente, não é bom nem secar, deixa assim." Já outro relato, falando sobre a mesma finalidade informa que: "quem tá com coceira, é até bom tomar um gole [...] que é pra botar o resto pra fora [...] aí faz a lavagem depois."

Os relatos acima evidenciam a importância da carobinha no tratamento de afecções da pele.

Já sobre Zollernia ilicifolia, houve relato em relação ao modo de preparo da mesma: "[...] chá da folha é fervida 5 minutos, porque ela é muito grossa [...]".

Como podemos observar na Tabela 1 , todos os informantes que utilizam como medicinal Z. ilicifolia, citaram fazer uso da folha como parte utilizada e decocto como forma de uso. Somavilla \& Canto-Dorow (1996) já haviam observado que a população justificava o uso do decocto, inclusive para partes tenras dos vegetais, com a afirmação de que, caso fosse feito um infuso o preparado resultaria inodoro e incolor e, portanto, ineficaz. No entanto, na região do Vale do Ribeira, esta planta é preparada por infusão das folhas e usada internamente contra úlceras e problemas estomacais (Di Stasi \& Hiruma-Lima, 2002).

A técnica da decocção para a preparação do decocto é restritiva, pois muitos princípios ativos podem ser alterados por aquecimento prolongado, ou por temperatura elevada. Geralmente, os únicos farmacógenos para os quais se aplica a técnica são raízes e cascas. Não se devem submeter ao processo de decocção ou cozimento drogas vegetais contendo essências, que se perderiam por volatilização, nem compostos oxidáveis, hidrolisáveis ou racemizáveis pela ação do calor (Prista et al., 1991). Segundo Simões et al. (2010), a forma de preparo de uma planta é importante para que as substâncias químicas responsáveis pelo efeito farmacológico, sejam corretamente retiradas do interior das células da planta, bem como para não modificar as propriedades químicas.

Quando questionados sobre reações adversas, duas plantas foram citadas pelos entrevistados, Cabralea canjerana (canjerana) e Casearia sylvestris (guaçatonga) por apresentarem efeitos indesejados. Um entrevistado citou um terceiro caso, sobre a incorreta identificação da árvore Sorocea bonplandii (mata-olho). Uma pessoa a utilizou, pensando ser Z. ilicifolia (carapicicade-folha-lisa/falsa espinheira-santa), devido à semelhança das duas árvores, ocorrendo, após a utilização da mesma, reações adversas.

Sobre Cabralea canjerana, temos o seguinte relato: "[...] ela é tóxica [...] e adstringente, ela é muito boa pro estômago, mas quem fez uso correto teve resultado, quem não fez correto, não teve resultado, deu até uns calorões na pessoa."

Já sobre Casearia sylvestris, quando questionado sobre os efeitos indesejados, o entrevistado relatou: "[...] quem fazia 1 litro de manhã (do chá) e ia tomando durante o dia, porque queria emagrecer, fez mal sim, daí deu diarréia, tontura, porque ela baixa a pressão."

Nestes dois casos, a ocorrência dessas reações adversas, pode ser justificada pela utilização incorreta da planta e pela grande frequência de seu uso, pois, segundo os entrevistados, quando utilizados de maneira correta não se observam problemas.

Segundo Veiga-Junior et al. (2005), o uso milenar de plantas medicinais mostrou ao longo dos anos que determinadas espécies apresentam substâncias potencialmente perigosas. Do ponto de vista científico, pesquisas mostraram que muitas delas possuem substâncias potencialmente agressivas e, por esta razão, devem ser utilizadas com cuidado, respeitando seus riscos toxicológicos.

Um relato interessante foi obtido sobre a incorreta identificação de Sorocea bonplandii (mata-olho): "[...] um homem (passou mal) tomou a outra planta pensando que era espinheira-santa, o mata-olho, é bem igualzinho, só que o mata-olho tem leite, e aquele leite é venenoso, tem que ter cuidado quando for apanhar, pra ter certeza que é a espinheira-santa (carapicica-de-folha-lisa) [...]".

Este dado reforça a importância de realizar a correta identificação das plantas medicinais, pois segundo Marodin \& Baptista (2001), a identificação botânica assume papel primordial uma vez que espécies diferentes com características morfológicas semelhantes são conhecidas popularmente pelo mesmo nome e uma mesma espécie recebe mais de uma denominação, devido a sua ação ou características morfológicas. Esta situação pode acarretar prejuízos aos usuários das plantas, pois é sabido que existe variação nos constituintes químicos que as compõem.

Além dos nomes populares descritos na Tabela 1 para as árvores medicinais, outros nomes foram atribuídos durante as entrevistas, como: olhode-pombo para Allophylus edulis; chá-de-bugre, pau-de-lagarto, café-do-mato e erva-de-lagarto

Rev. Bras. PI. Med., Campinas, v.16, n.2, supl. I, p.450-461, 2014. 
para Casearia sylvestris; formigueiro para Cecropia glaziov; palmito e ripa para Euterpe edulis; caroba para Jacaranda puberula e espinheira-santa para Zollernia ilicifolia, evidenciando a diversidade de nomes populares que as espécies localmente apresentam.

De acordo com Elisabetsky (2003), nomes populares, comuns, vulgares ou vernaculares são regionais e não recebem importância, de modo geral, nos trabalhos científicos. Por outro lado, eles são úteis e importantes nos trabalhos etnobotânicos, como fonte de informações sobre a cultura ou vocábulo de uma população, podendo dar indícios sobre a utilização popular de uma espécie.

Segundo Simões et al. (2010), as diferenças entre a espinheira-santa verdadeira (Maytenus ilicifolia Mart. ex Reissek) e as espécies conhecidas como mata-olho (Sorocea bonplandii) e a falsaespinheira-santa (Zollernia ilicifolia) praticamente só pode ser feita in vivo desde que se tenha conhecimentos de botânica. Z. ilicifolia possui estípulas, enquanto que a espinheira-santa verdadeira não possui. Quando se retira uma folha ou quebra-se um ramo de $S$. bonplandii, ocorre liberação da seiva na forma de um látex; o mesmo não ocorre com a espinheira-santa. Se os tecidos foliares estiverem secos, as dificuldades de distinção entre as espécies aumentam drasticamente, sendo impossível na maioria dos casos. De acordo com Silva Jr. (2003) estas duas espécies são consideradas adulterantes de produtos feitos à base da verdadeira espinheira- santa.

Em nosso estudo para a Casearia sylvestris Sw. (guaçatonga), das nove indicações terapêuticas citadas, exceto para a diabetes, oito delas foram encontradas na pesquisa bibliográfica realizada no trabalho de Figueiró-Leandro \& Citadini-Zanette (2008). No entanto, para a Zollernia ilicifolia

TABELA 2. Relação das espécies arbóreas, farmacógeno e indicações terapêuticas mencionadas pelos entrevistados, e registro destas na literatura consultada por Figueiró-Leandro \& Citadini-Zanette (2008).

\begin{tabular}{|c|c|c|c|}
\hline \multirow[b]{2}{*}{ Nome científico } & \multicolumn{2}{|l|}{ Entrevistas } & \multirow{2}{*}{$\begin{array}{l}\text { Confronto das indicações terapêuticas relatadas nas entrevistas } \\
\text { versus literatura consultada por Figueiró-Leandro \& Citadini-Zanette } \\
(2008)\end{array}$} \\
\hline & Farmacógeno & $\begin{array}{l}\text { Indicação } \\
\text { terapêutica }\end{array}$ & \\
\hline \multirow{2}{*}{$\begin{array}{l}\text { Allophylus edulis } \\
\text { (A.St.-Hil., Cambess. } \\
\text { et A. Juss.) Radlk. } \\
\text { (1) }\end{array}$} & Folhas & Diabetes & $\mathrm{NC}$ \\
\hline & Folhas & Adstringente & Körbes (1995). \\
\hline \multirow{2}{*}{$\begin{array}{l}\text { Cabralea canjerana } \\
\text { (Vell.) Mart. } \\
(1)\end{array}$} & Folhas & Adstringente & $\begin{array}{l}\text { Reitz (1965-1989), Pio Corrêa (1984). } \\
\text { Reis (1989-2011), Obs.: Porém são utilizados pelos autores: raiz, } \\
\text { caule e casca. }\end{array}$ \\
\hline & Folhas & Diabetes & $\mathrm{NC}$ \\
\hline \multirow{9}{*}{$\begin{array}{l}\text { Casearia sylvestris } \\
\text { Sw. } \\
(1,2,3,4)\end{array}$} & Folhas & Colesterol $(1,3,4)$ & $\begin{array}{l}\text { Silva Júnior (1997), Michalak (1997), Körbes (1995), Franco \& Fontana } \\
\text { (2001). }\end{array}$ \\
\hline & Folhas & Circulação (1) & $\begin{array}{l}\text { Körbes (1995), Michalak (1997), Silva Júnior (1997), Franco \& Fontana } \\
(2001) .\end{array}$ \\
\hline & Folhas & Coração $(1,2)$ & $\begin{array}{l}\text { Reitz (1950), Körbes (1995), Silva Júnior (1997), Michalak (1997), } \\
\text { Franco \& Fontana (2001). }\end{array}$ \\
\hline & Folhas & Pressão alta $(1,2)$ & Körbes (1995). \\
\hline & Folhas & Diabetes (2) & NC \\
\hline & Folhas & $\begin{array}{l}\text { Emagrecer }(2, \\
3,4)\end{array}$ & $\begin{array}{l}\text { Reitz (1950), Körbes (1995), Silva Júnior (1997), Michalak (1997), } \\
\text { Franco (2001), Franco \& Fontana (2001). }\end{array}$ \\
\hline & Folhas & Diurético $(1,3,4)$ & $\begin{array}{l}\text { Reitz (1950), Camargo (1985), Alice et al. (1995), Körbes (1995), Silva } \\
\text { Júnior (1997), Franco \& Fontana (2001), Teske \& Trentini (2001). }\end{array}$ \\
\hline & Folhas & Perna inchada (1) & Michalak (1997). \\
\hline & Folhas & $\begin{array}{l}\text { Mordida de inseto } \\
\text { (1) }\end{array}$ & Körbes (1995), Franco (2001), Franco \& Fontana (2001). \\
\hline \multirow{3}{*}{$\begin{array}{l}\text { Cecropia glaziovii } \\
\text { Sneth. } \\
\text { (1) }\end{array}$} & Raiz fresca & Reumatismo & NC \\
\hline & Raiz fresca & $\begin{array}{l}\text { Dor nas } \\
\text { articulações }\end{array}$ & NC \\
\hline & Coração (broto) & Tosse & Franco \& Fontana (2001). \\
\hline
\end{tabular}

continua...

Rev. Bras. PI. Med., Campinas, v.16, n.2, supl. I, p.450-461, 2014. 
TABELA 2. Relação das espécies arbóreas, farmacógeno e indicações terapêuticas mencionadas pelos entrevistados, e registro destas na literatura consultada por Figueiró-Leandro \& Citadini-Zanette (2008).

continuação...

\begin{tabular}{|c|c|c|c|}
\hline \multirow{3}{*}{$\begin{array}{l}\text { Cedrela fissilis Vell. } \\
\text { (1) }\end{array}$} & Folhas & Reumatismo & Lorenzi \& Matos (2008). \\
\hline & Folhas & Circulação & $\mathrm{NC}$ \\
\hline & Folhas & $\begin{array}{l}\text { Depurativo do } \\
\text { sangue }\end{array}$ & NC \\
\hline \multirow{4}{*}{$\begin{array}{l}\text { Euterpe edulis Mart. } \\
\text { (1) }\end{array}$} & Raiz & Reumatismo & NC \\
\hline & Raiz & Doença da gota & $\mathrm{NC}$ \\
\hline & Raiz & Chia & NC \\
\hline & Raiz & Colesterol & $\mathrm{NC}$ \\
\hline \multirow{8}{*}{$\begin{array}{l}\text { Jacaranda puberula } \\
\text { Cham. } \\
(1,2,5)\end{array}$} & Folhas & Alergias $(1,2,5)$ & $\mathrm{NC}$ \\
\hline & Folhas & Frieira (1) & $\mathrm{NC}$ \\
\hline & Folhas & Inflamação (2) & $\mathrm{NC}$ \\
\hline & Folhas & $\begin{array}{l}\text { doenças de pele } \\
\text { (2) }\end{array}$ & Cervi et al. (1989), Marcuzzo (1998). \\
\hline & Folhas & $\begin{array}{l}\text { Sarna/ Cobreiro } \\
\text { (5) }\end{array}$ & Cervi et al. (1989). \\
\hline & Folhas & Tosse (1) & NC \\
\hline & Folhas & $\begin{array}{l}\text { Bronquite alérgica } \\
\text { (1) }\end{array}$ & NC \\
\hline & Folhas & $\begin{array}{l}\text { Intoxicação do } \\
\text { veneno de roça (1) }\end{array}$ & NC \\
\hline \multirow{3}{*}{$\begin{array}{l}\text { Magnolia ovata } \\
\text { (A.St.-Hil.) Spreng. } \\
\text { (1) }\end{array}$} & Folhas & Cirrose hepática & $\mathrm{NC}$ \\
\hline & Folhas & Reumatismo & $\mathrm{NC}$ \\
\hline & Folhas & Infecção no útero & NC \\
\hline \multirow{3}{*}{$\begin{array}{l}\text { Ocotea indecora } \\
\text { (Schott) Mez. } \\
(2)\end{array}$} & Folhas & Dor no estômago & $\mathrm{NC}$ \\
\hline & Folhas & Resfriado & $\mathrm{NC}$ \\
\hline & Folhas & Gripe & NC \\
\hline \multirow{4}{*}{$\begin{array}{l}\text { Ocotea odorifera } \\
\text { (Vell.) Rohwer } \\
(1,2,3)\end{array}$} & Casca/Flores & Reumatismo $(1,3)$ & $\begin{array}{l}\text { Pio Corrêa (1984), Körbes (1995), Lorenzi \& Matos (2008), Backes \& } \\
\text { Irgang (2002). } \\
\text { Backes \& Irgang (2004). }\end{array}$ \\
\hline & Casca & $\begin{array}{l}\text { Doença da gota } \\
\text { (1) }\end{array}$ & Backes \& Irgang (2002), Backes \& Irgang (2004). \\
\hline & Casca/Flores & Artrose (3) & Körbes (1995). \\
\hline & Folhas & Tosse (2) & $\mathrm{NC}$ \\
\hline $\begin{array}{l}\text { Psidium cattleianum } \\
\text { Sabine }(1,2)\end{array}$ & Folhas & $\begin{array}{l}\text { Diarréia, } \\
\text { Dor de barriga } \\
(1,2)\end{array}$ & $\begin{array}{l}\text { Cervi et al. (1989), Alice et al. (1995), Backes \& Irgang (2002), Backes } \\
\text { \& Irgang (2004). }\end{array}$ \\
\hline \multirow{3}{*}{$\begin{array}{l}\text { Trema micrantha (L.) } \\
\text { Blume } \\
(1,2)\end{array}$} & Folhas & $\begin{array}{l}\text { Dor na coluna, } \\
\text { Bico de papagaio } \\
\text { (1) }\end{array}$ & NC \\
\hline & Folhas & Reumatismo (1) & Silva Júnior (1997), Backes \& Irgang (2004). \\
\hline & Folhas & $\begin{array}{l}\text { Fortalecer o } \\
\text { aleitamento (2) }\end{array}$ & ( \\
\hline \multirow{5}{*}{$\begin{array}{l}\text { Zanthoxylum } \\
\text { rhoifolium Lam. } \\
\text { (1) }\end{array}$} & Casca & Colesterol & $\mathrm{NC}$ \\
\hline & Casca & Dor no corpo & Citada como "analgésica" em Reitz (1965-1989), Reis (1989-2011). \\
\hline & Casca & Coração & $\mathrm{NC}$ \\
\hline & Casca & Circulação & NC \\
\hline & Casca & Câncer & NC \\
\hline
\end{tabular}


TABELA 2. Relação das espécies arbóreas, farmacógeno e indicações terapêuticas mencionadas pelos entrevistados, e registro destas na literatura consultada por Figueiró-Leandro \& Citadini-Zanette (2008).

continuação...

\begin{tabular}{llll}
\hline & \multicolumn{1}{l}{ Folhas } & Dor nas costas (1) & NC \\
\cline { 2 - 4 } & Folhas & Úlceras $(1,3,4)$ & Rodrigues et al. (2002), Coelho et al. (2003), Silva Junior (2006). \\
\cline { 2 - 4 } $\begin{array}{l}\text { Zollernia ilicifolia } \\
\text { (Brongn.) Vogel } \\
(1,2,3,4)\end{array}$ & Folhas & Dor de barriga (1) & NC \\
\cline { 2 - 4 } & Folhas & Artrite (1) & NC \\
\cline { 2 - 4 } & Folhas & Calmante (1) & NC \\
\cline { 2 - 4 } & Folhas & Tumor de esôfago & NC \\
& Folhas & Estômago (3, 4) & NC \\
\cline { 2 - 4 } & Folhas & Congestão (2) & NC \\
\hline
\end{tabular}

NC = Não consta na literatura consultada.

Os informantes foram codificados por números de 1 a 5 .

(carapicica-de-folha-lisa), das oito indicações terapêuticas mencionadas nas entrevistas deste trabalho, apenas uma (úlcera) está descrita na pesquisa de Figueiró-Leandro \& Citadini-Zanette (2008).

Conforme descrito na Tabela 2, das 14 árvores medicinais mencionadas pelos entrevistados, para Euterpe edulis (palmiteiro), Magnolia ovata (baguaçu) e Ocotea indecora (canela), não há registro de suas indicações terapêuticas na literatura consultada por Figueiró-Leandro \& Citadini-Zanette (2008).

Outras árvores também merecem destaque, pois a literatura contempla parcialmente as indicações citadas, sendo que na maioria dos casos as indicações não estão contempladas, evidenciando assim, a necessidade de mais estudos sobre essas plantas.

O conhecimento demonstrado pelos entrevistados e descrito neste estudo reforça a importância do registro do conhecimento popular, pois várias indicações terapêuticas relatadas, não são descritas na literatura. Consequentemente, a ausência deste, repercute na ausência de pesquisas inviabilizando que esta atinja o status de planta validada. A validação da eficácia e segurança das plantas medicinais, além de impulsionar novas pesquisas e descobertas na área da saúde e afins,

ANEXO 1. Questionário para aplicação às agentes da pastoral da saúde e à comunidade do bairro mina união:
1) Idade:
( ) 20 a 29 anos
( ) 30 a 39 anos
( ) 40 a 49 anos
( ) 50 a 59 anos
( ) 60 a 69 anos
( ) 70 a 79 anos
( ) 80 a 89 anos
( ) Acima de 90 anos
2) Sexo:
( ) Masculino
( ) Feminino
3) Estado Civil:
( ) Casado
( ) Viúvo
( ) Solteiro
( ) Outros:
( ) Separado
4) Onde voce reside? :
Localidade/Bairro:
Município
5) Você frequenta a Pastoral da Saúde? Se sim, em que bairro e município? :

6) Nasceu em perímetro urbano ou rural?:

7) Voce utiliza a como planta medicinal?

( ) Sim ( ) Não

8) Se sim. Há quanto tempo utiliza?

9) Conhece essa planta por outros nomes populares? Quais? 
ANEXO 1. Questionário para aplicação às agentes da pastoral da saúde e à comunidade do bairro mina união: continuação...

10) Costuma fazer uso da

( ) Às vezes

11) Usa em conjunto com outras plantas? Quais? no tratamento de doenças:
( ) Sempre

\section{( ) Nunca}

12) Para qual finalidade (doenças) a é utilizado individualmente?

13) Qual parte da planta é utilizada?:

\begin{tabular}{|l|l|l|}
\hline Farmacógeno & Forma de uso & Solvente utilizado \\
\hline Raiz seca & & \\
\hline Raiz fresca & & \\
\hline Caule (talo) & & \\
\hline Folhas & & \\
\hline Flores & & \\
\hline Frutos & & \\
\hline Planta inteira & & \\
\hline
\end{tabular}

Forma de Uso:
(1) Pomada
(2) Lavagem
(3) Compressas
(4) Tinturas
(5) Inalação
(6) Cataplasma

(7) Chás por infusão (coloca água fervendo sobre a planta)

$\begin{array}{ll}\text { (8) Chás por decocção (Ferve a planta) } & \text { (9) Garrafada }\end{array}$

14) Você cultiva esta planta em casa?:

( ) Sim ( ) Não

15) Se usa somente a planta seca, onde obtém?

( ) Em casa ( ) Farmácia ( ) Amigos ( ) Supermercados

( ) Outros:

16) Caso você não cultive a .............. em casa e se usa a planta fresca, onde ela é coletada para uso medicinal?

( ) quintais

( ) horta abandonada

( ) outros (dizer onde).

17) Com relação ao conhecimento do valor medicinal da informação:

( ) Familiares

( ) Livros especializados

( ) Outros:

( ) terrenos abandonados

18) Já teve algum caso de intoxicação (mal estar) na família pela utilização da planta ( alguém já passou mal utilizando a planta?) ?:
( ) Sim
( ) Não

19) Se respondeu afirmativo na questão anterior, que efeitos a planta produziu na pessoa intoxicada ( quais os sintomas apresentados?) ?:

20) Os resultados obtidos com o uso da são:
( ) Ótimos
( ) Bons
( ) Regulares ( ) Não fez efeito nenhum. 
repercute socialmente na utilização segura das plantas medicinais, no desenvolvimento regional, na valorização da espécie vegetal e dos saberes locais.

\section{REFERÊNCIA}

ALBUQUERQUE, U.P.; LUCENA, R.F.P.; LINS NETO, E.M.F. Seleção dos participantes da pesquisa. In: ALBUQUERQUE, U.P.; LUCENA, R.F.P.; CUNHA, L.V.F.C.(Orgs.) Métodos e Técnicas na Pesquisa Etnobiológica e Etnoecológica. Recife: NUPPEA, 2010. p.23-37.

ALICE, C.B.; SIQUEIRA, N.C.S.; MENTZ, L.A.; SILVA, G.A.A.B.; JOSÉ, K.F.D. Plantas medicinais de uso popular: Atlas Farmacognóstico. Canoas: ULBRA, 1995. 205p.

ALONSO, J. Fitomedicina: cursos para profissionais da área de saúde. São Paulo: Pharmabooks, 2008. 195p.

BACKES, P.; IRGANG, B. Árvores do sul: guia de identificação e interesse ecológico. Porto Alegre: Instituto Souza Cruz, 2002. 325p.

Mata Atlântica: as árvores e a paisagem. Porto Alegre: Paisagem do Sul, 2004. 396p.

CABALLERO, N.J. Perspectivas para el que hacer etnobotánico en México. In: BARRERA, A. (Ed.). La etnobotánica: tres puntos de vista y una perspectiva. Xapala: Instituto Nacional de Investigaciones sobre Recursos Bióticos, 1983. p.25-28.

CAMARGO, M.T.L. Medicina Popular: aspectos metodológicos para pesquisa, garrafada - objeto de pesquisa, componentes medicinais de origem vegetal, animal e mineral. São Paulo: ALMED, 1985. 130p.

CERVI, A.C.; NEGRELLE, R.R.B.; SBALCHIERO, D. Espécies vegetais utilizadas na terapêutica popular no município de Curitiba, Paraná, Brasil. Estudos de Biologia, v.23, p.5-42, 1989.

COELHO, R.G.; DI STASI, L.C.; VILEGAS, W. Chemical constituents from the infusion of Zollernia ilicifolia Vog. and Comparison with Maytenus species. Zeitschrift für Naturforschung, v.58, p.47-52, 2003.

CORREAA, A.D.; BATISTA, R.S.; QUINTAS, L.E.M. Plantas Medicinais do Cultivo à Terapêutica. 5.ed. Petrópolis: Vozes, 2002. 247p.

DI STASI, L. C. (Org.). Plantas Medicinais: Arte e Ciência. Um guia de Estudo Interdisciplinar. São Paulo: Unesp, 1996. 230p.

DI STASI, L.C.; HIRUMA-LIMA, C.A. Plantas medicinais na Amazônia e na Mata Atlântica. 2.ed. São Paulo: UNESP, 2002. 604p.

ELISABETSKY, Elaine. Etnofarmacologia. Ciência e Cultura [online]. v.55, n.3, p.35-36, 2003.

EPAGRI. Empresa de Pesquisa Agropecuária e de Extensão Rural de Santa Catarina. Dados e informações bibliográficas da unidade de planejamento regional litoral sul catarinense - UPR8. Florianópolis: EPAGRI, 2001. 1 CD ROM.

FIGUEIRÓ-LEANDRO, A.C.B.; CITADINI-ZANETTE, V. Árvores medicinais de um fragmento florestal urbano no município de Criciúma, Santa Catarina, Brasil.
Revista Brasileira de Plantas Medicinais, v.10, n.2, p.56-67, 2008.

FRANCO, I.J.; FONTANA, V.L. Ervas e Plantas -Amedicina dos simples. 6.ed.Erexim: EDELBRA, 2001. 207p.

FRANCO, L.L. As sensacionais $\mathbf{5 0}$ plantas medicinais de poder curativo. 5.ed. rev. ampl. Curitiba: Lobo Franco Ltda., v.1. 2001. 236p.

GUYTON, A.C.; HALL, J.E. Tratado de fisiologia médica. 9.ed. Rio de Janeiro: Guanabara Koogan, 1997. 1014p.

IBGE. Instituto Brasileiro de Geografia e Estatística. Estimativas das populações residentes: em 1 de julho de 2008, segundo os municípios. Brasília, 2008. Disponível em: <http://www.ibge.gov.br/home/ estatistica/ populacao/ estimativa2008/POP2008_DOU. pdf>. Acesso em: 10 nov. 2008.

KÖRBES, V.C. Plantas medicinais. 51.ed. Francisco Beltrão: Associação de Estudos, Orientação e Assistência Rural (ASSESOAR), 1995. 188p.

LORENZI, H.; MATOS, F.J.A. Plantas medicinais no Brasil: nativas e exóticas. 2.ed. Nova Odessa: Instituto Plantarum, 2008. 576p.

MS. Ministério da Saúde 0 que é a RENISUS? Brasília: Ministério da Saúde, 2009. Seção Portal da Saúde. Disponível em: <http://189.28.128.100/portal /saude/ profissional/visualizar_texto.cfm?idtxt=30780 $>$. Acesso em: 27 jul. 2009.

MARCUZZO, S.F. Árvores estratégicas da Mata Atlântica: por um verde mais vivo. Osório: Prefeitura Municipal de Osório, 1998. 34p.

MARODIN, S.M.; BAPTISTA, L.R.M. O uso de plantas com fins medicinais no município de Dom Pedro de Alcântara, Rio Grande do Sul, Brasil. Botucatu: Revista Brasileira de Plantas Medicinais, v.4, n.1, p.57-68, 2001.

MICHALAK, E. Apontamento fitoterápico da irmã Eva Michalak. Florianópolis: EPAGRI, 1997. 94p.

OMETTO, J.C. Bioclimatologia vegetal. São Paulo: CERES, 1981. 425p.

OMS Organización Mundial de La Salud. Situación regulamentaria de los medicamentos: uma reseña mundial. Organización Panamericana de la Salud. Washington: OPAS. 2000.

PIO CORREAA, M. Dicionário de plantas úteis do Brasil e das exóticas cultivadas. Rio de Janeiro: Ministério da Agricultura; IBDF, 1984. 6v.

PRISTA, L.V.N.; ALVES, A.C.; MORGADO, R. Técnica farmacêutica e farmácia galénica. 4.ed. Lisboa: Fundação Calouste Gulbenkian, v.1, 1991. 518p.

REIS, A. (Ed.) Flora Ilustrada Catarinense. Itajaí: Herbário Barbosa Rodrigues, 1989-2011.

REITZ, R. (Ed.) Plantas medicinais de Santa Catarina. Itajaí: Sellowia, v.2, n.2, p.71-116, 1950.

Flora Ilustrada Catarinense. Itajaí: Herbário Barbosa Rodrigues, 1965-1989.

RODRIGUES, L.A.; CARVALHO, D.A.; GOMES, L.J.; BOTREL, R.T. Espécies vegetais nativas usadas pela população local em Luminárias - MG. Boletim Agropecuário, n.52, p.1-34, 2002.

SANTA CATARINA (Estado). Atlas de Santa Catarina. Rio de Janeiro: Aerofoto Cruzeiro, 1986. 176p.

SILVA JÚNIOR, A.A (Coord.) Plantas medicinais. Itajaí: Sonopress; Epagri MMA/FNMA, 1997. 1 CD-ROM.

Essentia herba: plantas biotivas. Florianópolis:

Rev. Bras. PI. Med., Campinas, v.16, n.2, supl. I, p.450-461, 2014. 
Epagri, v.2, 2006. 663p.

SIMÕES, C.M.O.; MENTZ, L.A.; SCHENKEL, E.P.; IRGANG, B.E.; STEHMANN, J.R. Plantas da medicina popular no Rio Grande do Sul. 5.ed. Porto Alegre: UFRGS, 1998. 172p.

SIMÕES, C.M.O.; SCHENKEL, E.P.; GOSMANN, G.; MELLO, J.C.P.; MENTZ, L.A.; PETROVICK. P.R.(Orgs). Farmacognosia: da planta ao medicamento. 6.ed. Porto Alegre: Editora da UFRGS: Florianópolis: Editora da UFSC, 2010. 1104p.

SOMAVILLA, N.; CANTO-DOROW, T.S. Levantamento das plantas medicinais utilizadas em bairros de Santa Maria - RS. Ciência e Natura, v.18, p.131-48, 1996. TESKE, M.; TRENTINI, M. Herbarium: Compêndio de fitoterapia. 4.ed. Curitiba: INGRA, 2001. 317p.

VEIGA-JUNIOR, V.F.; PINTO, A.C.; MACIEL, M.A.M. Plantas medicinais: cura segura? São Paulo: Química Nova, v.28, n.3, p.519-528, 2005.

WHO World Health Organization Traditional Medicine Fact sheet $N^{\circ} 134$. World Health Organization: Geneva. 2003. 